or as consultants or medical officers in hospitals. Nearly 50 settled in Canada and the U.S.A. Some of them took up an academic career in North America, and eventually became associate professors. Five work in Africa in newly independent Commonwealth countries, five in Malaysia, five in Australia, one in New Zealand, three in the West Indies, and three in France. Eighteen graduates have died-a high mortality rate, considering that they were relatively young.

Five Polish professors of the School have died. Two professors live in Poland, one in Great Britain. Eight lecturers and five assistants have died, eight have returned to Poland. Some of the others have emigrated to the U.S.A. The rest live in Great Britain.

The creation of the Polish School of Medicine within the University of Edinburgh was a fine example of cooperation between nations in the academic sphere. It is to be hoped that such cooperation will not remain unique in the history of medicine, even though one must also hope that the need which gave rise to it will never be experienced again.

\title{
BIBLIOGRAPHY
}

Polish School of Medicine at the University of Edinburgh (1942). Edited by J. Brodzki. Oliver and Boyd, Edinburgh.

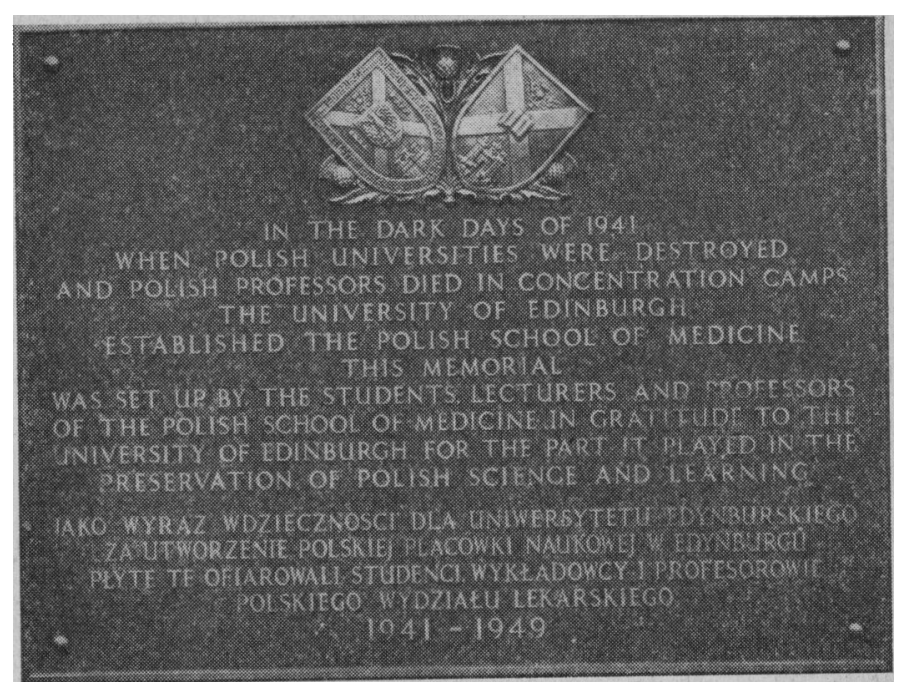

Memorial tablet unveiled in the quadrangle of the University Medical School Buildings.

The photographs were provided by the author and by the Polish Library, London.
An extensive knowledge of the literature is regarded by most researchers as a prerequisite to starting any kind of research work. It is also necessary for the practising physician if he is to keep up to date with treatment and care of patients. However, it is no longer possible to devote sufficient time to reading to keep abreast of the material published in any one field, however circumscribed. Although the number is not definitely known, each year at least four thousand medical periodicals are published, and new ones are appearing daily. Sir Theodore Fox" called his Heath Clark lectures "Crisis in Communication," and in them he examined closely the problems facing those concerned with the dissemination of medical information. Discussing the needs of the medical reader, he pointed out that his attention had first to be drawn to the existence of the material through abstracts, review journals, regularly issued bibliographies, and other methods, and then once a particular publication has been brought to his notice it should be readily available to him for use at his desk or laboratory bench.

\section{Computer System}

Some years ago the National Library of Medicine in Washington decided to overhaul the methods used in compiling the Index Medicus. Since the latter half of the nineteenth century it has kept the world informed of the output of medical literature month by month until in 1961 each issue contained references to more than 10,000 articles. Out of this study has come the Medical Literature Analysis and Retrieval

* Professor of Pathology (Dental School), University of Newcastle upon Tyne.
System (Medlars), which uses a Honeywell 800 computer to process, sort, and print out the material which forms each issue of Index Medicus. The computer also stores the information on magnetic tape which can be used to satisfy search demands.

At the National Library of Medicine it was thought likely that a bottle-neck might occur if all requests for bibliographies and literature searches were to be handled at one place, so copies of the tape have been made available to several other centres in the U.S. Largely through the initiative of Professor G. A. Smart, the Newcastle upon Tyne Faculty of Medicine decided that steps should be taken to see if the National Library of Medicine would allocate a tape to Newcastle to enable literature searches to be undertaken in this country. The project was enthusiastically welcomed by Professor Page, Director of the Computer Laboratory in Newcastle, and eventually it was announced in April 1965 by the Secretary of State for Education and Science that a Medlars service would be set up in Newcastle upon Tyne for an experimental period of three years. The University would receive a grant of $£ 26,000$ for its share of the work, and the National Lending Library for Science and Technology at Boston Spa would collaborate with the University Library on the library aspect of the project, Dr. A. J. Harley being seconded for this purpose. The time since then has been spent in preparing for the operation, which has just started.

\section{Technical Aspects}

The technical aspects of the project have recently been described by Harley and Barraclough. ${ }^{2}$ Dr. Harley, of the 
National Lending Library, visited Washington to study the project at the National Library of Medicine and since then has been training librarians in the use of the computer. Miss Barraclough also visited America, and has been responsible for virtually rewriting the Medlars Search programme so that it can be processed by the English Electric KDF9 computer in use at the University. $f$

A computer cannot give out more than has been put in, so that it is necessary to consider what is actually put into the computer at the National Library of Medicine. ${ }^{3}$ Every article in the journals indexed is translated into English as necessary, and certain basic information, such as title, author, date of publication, is fed into the computer. As well as this information, the abstractors note any mention of anything in Medical Subject Headings (MESH), which contains those headings or tags that are used in the compilation of Index Medicus. At present MESH is published annually and contains about 6,000 headings. Any article may yield on average from 10 to 30 subject headings or tags, and it is obvious that more of these tags can be stored on tape than it would be possible or desirable to use in Index Medicus if the size of the issues was not to increase beyond all convenience.

Once the material is on tape the computer can be programmed to sort the information in many different ways, to produce, for example, bibliographical lists of newly published material on a given subject at weekly or monthly intervals, or, alternatively, to use the considerable depth of indexing to produce the one or two articles which satisfy the needs of the research worker looking for the papers published in a very narrow field.

\section{Evaluation of Usefulness of the System}

Although the system has been in operation since 1964 to produce the Index Medicus there has been little attempt so far to evaluate its usefulness in literature retrieval. It is this latter aspect which particularly interests the Newcastle workers, and in order to help with this project users of the systemwhich will be free of charge for the two-year trial period

+Dr. Harley has arranged a series of courses at Boston Spa and at Newcastle for librarians who wish to take part in the service. Further details are obtainable from him. -will be expected to provide information on the success or otherwise of the process.

Users will give their requests to their usual medical librarian, who will probably be in a position to advise whether the request is suitable for Medlars. It may well be that the use of the available library resources such as Index Medicus or some of the abstract journals will produce the answer in a much shorter time. If a computer search is thought desirable the demand will be transmitted to Dr. Harley at the National Lending Library or to the University Library at Newcastle if the inquirer normally uses that library. The request will then be edited to a form suitable for the computer. Probably a batch of requests will be processed by the computer at regular intervals which will depend on the use made of the service. The printed-out bibliographies will be returned to the inquirer via his librarian with a request for information about the usefulness of the result.

It will be obvious that this method of retrieval will be worth the effort and expense only if it produces results superior to the more conventional methods. By analogy to map-reading the larger the reference number and the greater the scale of the map the more accurate will be the pinpointing of any location. The difficulty here lies in the appropriateness of the tags in MESH. A great responsibility lies on the indexers to recognize and indicate appropriate material under the available headings. One is reminded of the treatment meted out by Procrustes to his enforced guests, and if too great distortion is used to fit subjects into the available headings the results will be distorted too. Again, if search requests are too woolly and indefinite, crisp answers will not be forthcoming. This is a precision tool, which will give of its best only if used intelligently and delicately. Its limitations are not yet fully understood and it is an exciting and worth-while project to help in the evaluation.

\section{REFERENCES}

Fox, Sir Theodore, Crisis in Communication, 1965. Athlone Press, London.

Harley, A. J., and Barraclough, Elizabeth D., Postgrad. med. Y., 1966, 42, 69.

s The Medlars Story at the National Library of Medicine, 1963. U.S. Department of Health, Education, and Welfare. Public Health Service. U.S. Government Printing Office. 0-634850.

\section{CONFERENCES AND MEETINGS}

\section{Pharmacological Control of Blood-pressure}

[From a SPECIAL CoRrespondent]

The annual scientific meeting of the Faculty of Anaesthetists of the Royal College of Surgeons of England was held at the College on 7 May. The subject was "Pharmacological Control of Blood-pressure," with Dr. R. P. W. SHACKLETON (Chairman of the Education Committee) in the chair.

Professor J. H. BuRN, F.R.S. (Oxford), discussed the normal mechanisms of the control of blood-pressure, which he said was largely mediated by the pressor amines and polypeptides. Until recently the fate of noradrenaline and adrenaline had remained unknown, but he himself had suggested in 1932 that both substances were taken up by the postganglionic fibres themselves. It was also now recognized, Professor Burn continued, that one group of amines-such as noradrenaline and metaraminol-acted directly on the blood-vessel walls, and others-for example, methedrine-acted by producing a release of noradrenaline from the nerve endings. Hence when an infusion of noradrenaline failed to affect the blood-pressure any more the pressure could still be raised by the administration of methedrine. Professor Burn then considered the importance of calcium ions in the maintenance of bloodpressure. Acetylcholine had been shown to increase the permeability of the chromaffin cells of the medulla of the adrenal gland to calcium ions; this led to the release of adrenaline and noradrenaline from the cells. Thus intravenous calcium gluconate probably raised the blood-pressure in two main ways, first by affecting the peripheral blood- vessels and secondly. by its action on the heart.

\section{Disturbed Regulation}

Disturbed blood-pressure regulation was then considered by Professor W. S. PeArT (St. Mary's Hospital, London), who outlined the factors affecting cardiac output and peripheral vascular resistance, which together determined the blood-pressure. The sympathetic nervous system was clearly important, but no methods were available for assessing its overall activity in the body at any one time. Moreover, experiments to remove the sympathetic nervous system completely, either surgically or by immunological means, left animals with normally reacting blood- 